\title{
Climate Changes: How the Atmosphere Really Works
}

\author{
Ernani Sartori \\ Universidade Federal da Paraíba, João Pessoa, Brazil \\ Email: e.solar@hotmail.com
}

Received 7 April 2015; accepted 23 April 2015; published 24 April 2015

Copyright (C) 2015 by author and Scientific Research Publishing Inc.

This work is licensed under the Creative Commons Attribution International License (CC BY). http://creativecommons.org/licenses/by/4.0/

(c) (i) Open Access

\section{Abstract}

Top concepts adopted by the current science on climate changes or atmospheric warming are not in agreement with the first principles of the physics. This paper presents a new understanding on the atmospheric behaviors. For example, the radiation is not the only factor that influences the air temperature, as the law of conservation of energy defines and as shown physically and mathematically in this article. The Sun is not the only heat source for the atmosphere because there is generation of heat at the Earth's surface by human activities. It is also shown that the water vapor is not a null effect and that the water vapor cannot be removed from the atmosphere for air temperature, greenhouse effect and climate changes considerations, in contrast to the current literature beliefs. The "feedback" concept is unfounded and invalid. The literature also says that "water vapor increases as the Earth's atmosphere warms", but this is also incorrect. The above equivocated understanding is accompanied by another one which believes that more water evaporates if the air temperature increases, but it is not in this way. These demonstrations and other authors' surveys showing that in the last decades the planet became wetter eliminate the literature concept that the water vapor does not have influence on the atmospheric warming/cooling. The conventional water cycle is related to the mass of water (mass of evaporation $\Leftrightarrow$ mass of precipitation) and then the physical and mathematical principles of the new hydrological cycle that includes the direct human influence are shown. The same is done for the carbon cycle. It is solved the problem on why the wind speed on Venus is very high above the cloud deck while it is stagnant below it, being this the same physical principle valid for the Earth's cloud cover. In the atmosphere, all the corresponding principles are the same, only their amounts change. It is demonstrated that the $\mathrm{CO}_{2}$ is not decisive for building and changing the temperatures of Venus, Mars, Mercury, Jupiter and Earth. Ice cores are not valid for "determining" "past" temperatures of the planet, because the mass of their air bubbles may be old, but the corresponding temperatures are not.

\section{Keywords}

Climate Change, Global Warming, Evaporation, Wind, Temperature, Radiation, Precipitation, 
Rain, Greenhouse Effect, Hydrological Cycle, Cloud Cover, Ice Cores, Planets

\section{Introduction}

The science must advance to follow its mission of finding the correct ways and solutions for the development and benefit of the humankind. This paper goes in this direction elucidating and solving scientifically many unclear, doubtful, equivocated, empiricist and unsolved top concepts related to climate changes. In this way, as soon as the science becomes more sound, transparent and coherent, the skepticism will reduce drastically. A true science must be able and must have the mission to explain correctly, fluently, coherently, completely, accurately and with humility all the issues that it raises without imposing barriers. There isn't a side that is absolute and can impose everything indefinitely and another one that must adopt everything from the first side without the right of reasoning, analyzing and correcting. On the contrary, both sides must demonstrate accurately the true science and then the best of them must be used for the benefit of the civilization, as is done in the present work.

It is known that the referred area corresponds to a new and complex field of study and then not everything becomes completely clear and fully explained at a first glance, as observed in the corresponding current literature. But developments must continue and then contributions for the complete understanding of the problems should be taken simply as mutual collaborations, as is the scope of this article. In this paper, several adopted concepts by the current literature on the subject (e.g., [1]-[3]) are reviewed. Top issues such as: only the radiation influences the air temperature, the water vapor has a null effect for the greenhouse effect, the "forcing" and "feedback" concepts, water vapor and $\mathrm{CO}_{2}$, "water vapor increases as the atmosphere warms", "evaporation paradox", air temperature effect on evaporation, greenhouse effect, cloud cover influence, Venus' atmosphere, validation of ice cores, etc., are explained scientifically and coherently based on the first principles of the physics. A true science must not sustain equivocated concepts.

The current literature on global warming or climate changes is characterized by works dealing with experimental observations and their empirical methods, but the real atmospheric data are extremely vast, specific, variable, random, complex, isolate from each other, and alone do not produce a clear, firm, of general application and of unique understanding and direction. On the other hand, the theory provides the correct understandings and concepts as well as the proper directions on which ones we must follow. The first principles are those that make a car to run, a building to stand up, a rocket to lift up, a true nation to be built and the atmospheric behaviors to be understood and explained correctly and coherently. Theoretical concepts are able to verify the validation, application and importance of the real data without losing the correct direction and a lot of time, while the dependence almost exclusive on experimental observations does not lead us to the proper path and requires an infinite time to try to find even a simple and reliable final conclusion, which one normally is not found. Such conclusion normally is not found due to the extreme variability, isolate nature and complexity of the atmospheric behaviors, which ones do not have a direct and clear relationship with one another. Only a guide called theory can drive us on the proper line or direction. However, the theory must also be checked with the corresponding experimental data to verify its validation and application, and this has been done by this author in various works, such as in [4]-[7] and in the present one, where excellent and coherent results and agreements are obtained.

Yes, that's incredible, humans can influence the climate, but not as has been said by the current literature until to date. For example, if one drop of water is thrown upward, one drop of water will come back, and humans have thrown millions of tons of water and other substances upward every second around the globe, and then much water has come back irregularly in amounts, time and space. This is easy to understand and to agree and is scientifically expressed by the New Hydrological Cycle discovered by Sartori and demonstrated physically and mathematically even for the conventional water cycle for the first time in a scientific journal [7]. This is totally different than the corresponding literature belief which removes the water from the atmospheric heat and mass balances and even so says that excess of floods, for example, and other climate changes, all them originate from a warming due to a "greenhouse effect caused by the $\mathrm{CO}_{2}$ ". Such understanding is flawed because carbon dioxide and heat do not create mass. Therefore, such climate changes and other atmospheric behaviors and influences of substances on the climate are not just as we have heard until to date. This and much more are what the correct physical principles reveal scientifically.

The science must not march onto a fixed way, otherwise the great discoveries and advances in the history 
would have not been possible. The current science on the subject must have open mind and heart to allow new discoveries and knowledge that contribute for the development and advance of all.

\section{The Physical and Mathematical Demonstrations}

The current literature represents an Earth's greenhouse effect through a layer of $\mathrm{CO}_{2}$ circling the planet and where only the radiation takes place to influence the air temperature and all climatic changes, or through a common greenhouse without water (e.g., [1]). This is incorrect and inaccurate because not only the radiation acts to influence the air temperature and other phenomena as well as the water vapor cannot be removed from the atmosphere for mass and heat balances and consequently for air temperature considerations. The atmosphere works according to heat and mass balances and these processes are interrelated, not isolated from each other. Thus, considering the energy balance in steady state for the Earth's surface we have

$$
S=q_{e}+q_{r}+q_{c}+q_{k}
$$

that is, the energy received from the Sun by the Earth's surface must be equal to the corresponding heat lost through its different modes, and where $S=$ solar radiation received by the Earth's surface, $\mathrm{W} / \mathrm{m}^{2} ; q_{e}=$ latent heat loss by evaporation, $\mathrm{W} / \mathrm{m}^{2} ; q_{\mathrm{r}}=$ sensible heat loss by radiation, $\mathrm{W} / \mathrm{m}^{2} ; q_{c}=$ sensible heat loss by convection, $\mathrm{W} / \mathrm{m}^{2} ; q_{k}=$ sensible heat loss by conduction through the soil, $\mathrm{W} / \mathrm{m}^{2}$.

As can be seen from Equation (1), other heat transfer modes besides the radiation affect the atmospheric warming/cooling processes and consequently the air temperature. So, if we take any value for the solar radiation, let's say $S=700 \mathrm{~W} / \mathrm{m}^{2}$, the summation of the energy released by the surface to the atmosphere and to the ground must equal $700 \mathrm{~W} / \mathrm{m}^{2}$. Thus, if we have, for example,

$$
700=400+175+124+1
$$

then

$$
700=700 .
$$

So, we can easily see that if only the radiation heat transfer is considered the energy balance does not match and the resulting air temperature becomes erroneous. Furthermore, since the heat released per square meter as well as per total Earth's surface area is mostly by evaporation (in solar stills it is about $60 \%$ of the total heat emitted — calculated and well referenced [5] [8]; this same proportion is verified for the ambient temperatures of the Amazon [9]), the water cannot be ignored and the water vapor cannot be removed from the atmosphere for mass and heat balances and for air temperature, greenhouse effect and climatic changes considerations, in contrast to what is done by the literature and its "feedback" concept. This heat by evaporation and the corresponding variation of water vapor in air act every instant for building and changing the air temperature, which is the result of all heat and mass interactions in the atmosphere. All the atmospheric components participate in the mass and heat exchanges, and consequently for the formation and changing of the air temperature, not only one. Such amounts of water at the surface and of water vapor in the atmosphere obviously form the main component that builds and changes the air temperature. This is mandatory by the physics and cannot be neglected or modified by imaginative conceptualizations. Also, since Equation (1) represents the law of conservation of energy and the literature takes into account only its radiation effect, such attitude violates this fundamental law and behavior of the nature, and thus everything that comes from such violation is inaccurate.

The Sun is obviously the only external and natural heat source for the planet and atmosphere, however, on Earth's surface there is also generation of heat due to certain human activities such as fossil fuel and nuclear power plants, industries, vehicles, etc., that add heat to the atmosphere and consequently influence the air temperature, too. Thus, Equation (1) must be modified to:

$$
S+H=q_{e}+q_{r}+q_{c}+q_{k}+q_{L}
$$

where $H=$ heat generated at or added to the surface by human activities, $\mathrm{W} / \mathrm{m}^{2} ; q_{L}=$ latent heat loss from the surface due to the steam, $\mathrm{W} / \mathrm{m}^{2}$.

This energy added to the Earth's surface comes from the energy existent in the subsoil coal, oil, gas, uranium, etc., which is converted into heat by human activities. This heat is released to the atmosphere by radiation, convection and latent heat. The consequence is a warming of portions of the atmosphere. And extra heat generates clouds, rain, strong winds [7]. So, certain human actions can alter the heat and mass balances of the atmosphere and as a result alter its humidity, temperature and natural behaviors, directly and indirectly. 
This is clear and very different than the current science thinking for which almost only one gas and the corresponding radiation must be considered for deciding about the planet's air temperature and everything else about climatic issues. Therefore, all of these factors, variables and atmospheric components must be taken into account for computing the air temperature and climate changes, including the water vapor and the cloud cover strong influence, which elements also vary according to the new totals, as demonstrated in [7].

Furthermore, in the literature, the "forcing" effect is considered for an increasing level of $\mathrm{CO}_{2}$ in the atmosphere due to human activities, while the "feedback" effect, that is, a cyclic effect without human influence is taken into account for the water vapor. However, as demonstrated [7], the atmosphere works according to the working principles of the solar still (closed evaporator) and of an open evaporator (depending on the cloud cover and water vapor conditions), being both systems demonstrated in depth [5] [7]. All the corresponding atmospheric processes are the same, only their amounts change and although the thermal processes of the closed (solar still) and open evaporators are the same as the ones that happen in the atmosphere, some remarks should be done for the harmonization of these two solar applications with the planet's conditions. The bases or bottoms of a solar still and of an open evaporator are completely filled with water but the Earth's surface is a little bit different. About $70 \%$ of the Earth's surface are composed by water while for the land portion we could roughly estimate that $15 \%$ of it correspond to vegetation and 15\% correspond to deserts and constructions. Hence, about $85 \%$ of the planet emit heat and mass by evaporation to the atmosphere, which amount obviously makes the greatest and main component of the air temperature in humid places. Sartori [7] also shows that the water vapor added to the atmosphere is not only by evaporation, but also from the constructed part where lots of fossil fuel and nuclear plants, industries, vehicles, etc, around the world constantly throw thousands of tons of water vapor directly to the atmosphere, which ones come back irregularly in amounts, time and space and thus modify the natural hydrological cycle. These direct human influences also alter the atmospheric heat and mass balances and consequently the air temperature and the atmospheric behaviors. Really, the radiation is not the only factor influencing the air temperature and the water vapor cannot be removed from the atmosphere for deciding about the air temperature and climate changes.

The mass (and corresponding heat) balances below elucidate this issue still more. All the heat and mass processes in the atmosphere work in cycles, and as an example the hydrological cycle for a layer of the atmosphere can be expressed as follows (demonstrated physically and mathematically for the first time in a scientific journal [7]):

Rate of water mass accumulation (clouds + water vapor) = Rate of water mass in (evaporation) - Rate of water mass out (precipitation),

or

$$
\mathrm{d} M_{w, a} / \mathrm{d} \theta=\mathrm{d} M_{e v} / \mathrm{d} \theta-\mathrm{d} M_{p} / \mathrm{d} \theta
$$

where $M_{w, a}=$ accumulated water mass in a selected layer of the atmosphere $(\mathrm{kg}$ or $\mathrm{ppm}), M_{e v}=$ mass of water by evaporation ( $\mathrm{kg}$ or $\mathrm{ppm}), M_{p}=$ mass of water by precipitation (kg or ppm), and $\theta=$ time (h).

To take into account the direct human influence that alters the natural processes and their natural amounts, velocities, regularities and distributions, the New Hydrological Cycle was discovered by the present author and subsequently demonstrated physically and mathematically [7]. Its equation for a layer of the atmosphere is repeated below:

Rate of water mass accumulation (clouds + water vapor) = Rate of water mass in (evaporation) + Rate of water mass in (total clouds and water vapor caused by human activities) - Rate of water mass out (precipitation), or

$$
\mathrm{d} M_{w, a} / \mathrm{d} \theta=\mathrm{d} M_{e v} / \mathrm{d} \theta+\mathrm{d} M_{h} / \mathrm{d} \theta-\mathrm{d} M_{p} / \mathrm{d} \theta
$$

Since everything that rises comes back, the more intense and irregular the water mass, heat and particulate matter released to the atmosphere by human activities $\left(M_{h}\right)$, the more intense and irregular will be such return to the surface after physical and chemical interactions in the atmosphere.

Equation (3) can also be established for any other gas of the atmosphere including the $\mathrm{CO}_{2}$, which one can be named as "the natural $\mathrm{CO}_{2}$ cycle" (no human influence):

Rate of mass of $\mathrm{CO}_{2}$ (carbon dioxide) accumulation = Rate of $\mathrm{CO}_{2}$ mass in (upward naturally) - Rate of $\mathrm{CO}_{2}$ mass out (downward naturally),

or 


$$
\mathrm{d} M_{c d, a} / \mathrm{d} \theta=\mathrm{d} M_{c d, \text { in }} / \mathrm{d} \theta-\mathrm{d} M_{c d, \text { out }} / \mathrm{d} \theta
$$

where $M_{c d, a}=$ accumulated $\mathrm{CO}_{2}$ mass in a selected layer of the atmosphere (kg or ppm), $M_{c d, i n}=$ mass of $\mathrm{CO}_{2}$ in (upward naturally, $\mathrm{kg}$ or $\mathrm{ppm}$ ), $M_{c d, \text { out }}=$ mass of $\mathrm{CO}_{2}$ out (downward naturally, $\mathrm{kg}$ or $\mathrm{ppm}$ ).

Since certain human activities such as fossil fuel power plants, industries, vehicles, etc., release to the atmosphere greater and faster amounts of $\mathrm{CO}_{2}$ than the natural cycles can do, Equation (5) must be changed to:

Rate of $\mathrm{CO}_{2}$ mass accumulation = Rate of $\mathrm{CO}_{2}$ mass in (upward naturally) + Rate of $\mathrm{CO}_{2}$ mass in (sent upward by human activities) - Rate of $\mathrm{CO}_{2}$ mass out (withdrawn naturally and/or artificially),

or

$$
\mathrm{d} M_{c d, a} / \mathrm{d} \theta=\mathrm{d} M_{c d, i n} / \mathrm{d} \theta+\mathrm{d} M_{c d, h} / \mathrm{d} \theta-\mathrm{d} M_{c d, o u t} / \mathrm{d} \theta
$$

where $M_{c d, h}=$ mass of $\mathrm{CO}_{2}$ released to the atmosphere by human activities ( $\mathrm{kg}$ or ppm).

If one drop of water and one ppm of $\mathrm{CO}_{2}$ are thrown upward by humans, one drop of water and one ppm of $\mathrm{CO}_{2}$ must come back, only their rates change. After industrialization, certain human activities have released much more than one drop of water and one ppm of $\mathrm{CO}_{2}$ upward and faster than the natural cycles can do. In reality, thousands of tons of water vapor and other gases and particulate matter every instant around the globe. For example, the nuclear and fossil fuel power plants that convert liquid water into steam account for $40 \%$ of the US freshwater usage, while in Europe these plants account for about 50\% of the freshwater usage [10]. In Europe there are proportionally more nuclear plants in contrast to the higher number of fossil fuel power plants in the USA, and nuclear plants release more water vapor than fossil fuel plants. A part of this water is "recycled", but a great part of these enormous volumes and heat is sent upward and humidifies and warms the atmosphere, influencing the atmospheric processes directly, its natural behavior and its heat and mass balances. Additionally, [11] showed that the $20^{\text {th }}$ Century became wetter and [12] showed that almost the entire planet became wetter in the last 40 years. The lifetime of $\mathrm{CO}_{2}$ in the atmosphere is not yet scientifically defined and what matters are the concentrations of the gases in the atmosphere at each time. These atmospheric conditions are variable, not constant or fixed in time and space.

The surveys [11] [12] eliminate the literature thinking that the water vapor does not influence the atmospheric warming/cooling because it would remain only about 10 days in the atmosphere. Such consideration also contributed to the equivocated understanding that the water vapor is a "feedback". If the water vapor remained only such a number of days or if human sources were not able to add mass (and heat) of water and not influence the atmospheric behaviors, the atmosphere would not have become wetter in the last times. The human influence that humidifies the atmosphere through direct emissions of water vapor changes the atmospheric mass balance and consequently its heat balance. The $\mathrm{d} M_{w, a}$ and $\mathrm{d} M_{c d, a}$ express the amounts of water vapor and $\mathrm{CO}_{2}$ in the atmosphere at each time, respectively, which ones obviously vary according to the corresponding more or less intense emissions and removals of $\mathrm{H}_{2} \mathrm{O}$ and $\mathrm{CO}_{2}$. Since in the last decades the humidity and the clouds have increased (see [7]), the water vapor has had greater participation in the mass and heat exchanges and thus in the air temperature.

Furthermore, if the water vapor amount in the atmosphere was constant and if humans did not have influence on the atmospheric mass and heat balances directly and indirectly, the evaporation, the cloud cover and the precipitation amounts would remain always the same, but it is well-known and well referenced and explained [7] that in the last 50 years the evaporation has decreased while the clouds and precipitation have increased in some parts of the world, which differences or apparent inconsistencies led to the "evaporation paradox" concept and its non-sense "solutions" (e.g., [13] [14]) as well as led the present author to discover the New Hydrological Cycle.

This evaporation decrease can also be verified mathematically as follows. When a water surface is exposed to the atmosphere it suffers direct influence from the environmental parameters and then several ambient conditions are simulated here in order to calculate the corresponding evaporation from an open evaporator under an open and a "closed" atmospheres. The Sartori equation [4] [7] [8] [15] is the only one that takes into account the environmental factors that influence evaporation, and it also showed to be very accurate and the most accurate equation in comparison to experimental data and to lots of empirical formulas [4] [7], and then it is used here for this demonstration. This Sartori equation, among other things, is based on the boundary layer theory in the same way as the Sartori equation [6] is for the convection coefficient, which one also proved to be the most accurate in comparison to lots of empirical expressions (obtained from specific experiments and corresponding methods) carried out by the excellent work [16] and by [6] [17]: 


$$
E=0.0041 V^{0.8} L^{-0.2}\left(P_{w}-\phi P_{a}\right) / P
$$

where $E$ = evaporation rate, $\mathrm{kg} / \mathrm{m}^{2} \cdot \mathrm{s} ; V=$ wind velocity, $\mathrm{m} / \mathrm{s} ; L=$ water surface length in the wind direction, $\mathrm{m}$; $P_{w}=$ partial pressure of the air at the water temperature $t_{w}$, Pascal; $P_{a}=$ partial pressure of the air at the air temperature $t_{a}$, Pascal; $P=$ atmospheric pressure, Pascal; $\phi=$ relative humidity, fraction.

Let's consider common conditions of $t_{w}=20^{\circ} \mathrm{C}, t_{a}=25^{\circ} \mathrm{C}, V=2.5 \mathrm{~m} / \mathrm{s}, \phi=0.60$ and let's calculate the evaporation for a free water surface of $L=1.2 \mathrm{~m}$. Any chosen length applied to all situations as done here will produce the same relative results. Thus, applying Equation (7) we have

$$
\begin{aligned}
& E=0.0041(2.5)^{0.8}(1.2)^{-0.2}(2335.81-0.60 \times 3165.07) / 101325 \\
& E=0.00003546 \mathrm{~kg} / \mathrm{m}^{2} \cdot \mathrm{s}=0.127671 \mathrm{~kg} / \mathrm{m}^{2} \cdot \mathrm{h}
\end{aligned}
$$

If we admit that only the air temperature increases, then for $t_{a}=28^{\circ} \mathrm{C}$ we obtain:

$$
\begin{aligned}
& E=0.0041(2.5)^{0.8}(1.2)^{-0.2}(2335.81-0.60 \times 3777.02) / 101325 \\
& E=0.000005651 \mathrm{~kg} / \mathrm{m}^{2} \cdot \mathrm{s}=0.020343 \mathrm{~kg} / \mathrm{m}^{2} \cdot \mathrm{h}
\end{aligned}
$$

As is evident from the evaporation laws, from previous demonstrations and from these calculations, increasing the air temperature alone, the evaporation decreases. Since the evaporation is proportional to the difference $\left(t_{w}-t_{a}\right)$ because pressure is function of temperature, it is evident that when $t_{a}$ increases and $t_{w}$ remains the same, the evaporation must decrease. For the given example, it is verified that for an increase of only $3^{\circ} \mathrm{C}$ in the air temperature, the evaporation decreases more than 6 times.

However, it is known that increasing the wind velocity the evaporation increases. Then, let's double the wind velocity for the same conditions C2 to know what happens:

$$
E=0.000009839 \mathrm{~kg} / \mathrm{m}^{2} \cdot \mathrm{s}=0.035423 \mathrm{~kg} / \mathrm{m}^{2} \cdot \mathrm{h}
$$

Doubling again:

$$
E=0.00001713 \mathrm{~kg} / \mathrm{m}^{2} \cdot \mathrm{s}=0.061683 \mathrm{~kg} / \mathrm{m}^{2} \cdot \mathrm{h}
$$

And again:

$$
E=0.00002983 \mathrm{~kg} / \mathrm{m}^{2} \cdot \mathrm{s}=0.107376 \mathrm{~kg} / \mathrm{m}^{2} \cdot \mathrm{h}
$$

As can be seen, even doubling, quadruplicating, multiplying by eight and increasing even more the average wind velocity, the evaporation decreases in relation to that of the common conditions C1, due to the strong air temperature influence on evaporation.

In a scenario of increased greenhouse effect due to the cloud cover increase in a humid place, the temperatures and the air humidity increase, too. These are properties of greenhouses where there is evaporation, e.g., a solar still, and that caused by a cloud cover increase, too [5] [7]. It is also known that the $20^{\text {th }}$ Century and most of the world became wetter and with increased precipitation (e.g., [11] [12]), especially in the last decades. Also, according to the IPCC, from $1950-2000$ the air temperature increased $0.75^{\circ} \mathrm{C}$ and it could increase up to $6^{\circ} \mathrm{C}$ by 2100. If we consider that for every 50 years the air temperature increases $0.75^{\circ} \mathrm{C}$, then by 2100 the world would experience an air temperature $1.50^{\circ} \mathrm{C}$ higher, however, let's adopt an increase of $5^{\circ} \mathrm{C}$ in relation to the common conditions $\mathrm{C} 1$ and then consider $t_{w}=25^{\circ} \mathrm{C}, t_{a}=30^{\circ} \mathrm{C}, V=2.5 \mathrm{~m} / \mathrm{s}, \phi=0.70$ :

$$
\begin{aligned}
E & =0.0041(2.5)^{0.8}(1.2)^{-0.2}(3165.07-0.70 \times 4239.65) / 101325 \\
E & =0.00001603 \mathrm{~kg} / \mathrm{m}^{2} \cdot \mathrm{s}=0.057695 \mathrm{~kg} / \mathrm{m}^{2} \cdot \mathrm{h}
\end{aligned}
$$

As shown, increasing the air temperature and even the water temperature and the humidity, the evaporation decreases in relation to the one with the common conditions C1, in contrast to the general belief. The main message withdrawn from this result is that it is a strong error to state that the evaporation must increase based solely on $t_{a}$ and not taking into account the true influence of $t_{a}$ and of other variables that strongly affect the evaporation in the opposite sense at the same time. The influence of all of these variables and conditions can be easily and correctly verified only through Equation (7), and not through the known empirical formulas.

Let's now duplicate the wind velocity for this same scenario C6 to see what happens: 


$$
E=0.00002790 \mathrm{~kg} / \mathrm{m}^{2} \cdot \mathrm{s}=0.100439 \mathrm{~kg} / \mathrm{m}^{2} \cdot \mathrm{h}
$$

As we can see again, even increasing more than twice the average wind velocity in a scenario of increased air and water temperatures and humidity (but without an established greenhouse effect due to a full cloud cover), the evaporation still decreases in relation to that of the common conditions C1.

In all of these calculations the standard atmospheric pressure $(P)$ has been used, but when the water vapor in the air increases this generates the increase of $P$ (Equation (9)) which rise causes further evaporation decrease (Equation (7)).

The calculations C1-C7 have been performed considering deep water bodies, which high thermal inertias make their water temperatures to rise and fluctuate less and slower than shallow water surfaces ones, and then generate less evaporation than shallow water bodies. Less evaporation with more water leads to wetter ambient conditions, being these results in close agreement with the observations that "increasingly wet conditions have been found over the Amazon Basin" [1], and that the $20^{\text {th }}$ Century became wetter [11] as well as increased precipitation (and thus humidity) has been observed over most countries of the world in the last decades [12]. For shallow water surfaces, the water temperatures attain higher values and more rapidly than deep waters and then for these systems the evaporation should be higher than that for the common conditions for deep water bodies C1. To verify mathematically, let's consider the following conditions: $t_{w}=32^{\circ} \mathrm{C}, t_{a}=30^{\circ} \mathrm{C}, V=2.5 \mathrm{~m} / \mathrm{s}, \phi=0.70$. So,

$$
\begin{aligned}
E & =0.0041(2.5)^{0.8}(1.2)^{-0.2}(4750.96-0.70 \times 4239.65) / 101325 \\
E & =0.0001448 \mathrm{~kg} / \mathrm{m}^{2} \cdot \mathrm{s}=0.521132 \mathrm{~kg} / \mathrm{m}^{2} \cdot \mathrm{h}
\end{aligned}
$$

As shown and expected, the evaporation from shallow water surfaces is much higher and since these kinds of water reservoirs are predominant in dry regions, these places tend to become still drier (more evaporation with less water leads to drier soil and ambient conditions), unless wind currents change the traditional local atmospheric conditions.

The IPCC says that from 1950-2000 the sea surface temperature increased $0.5^{\circ} \mathrm{C}$, while the air temperature increased $0.75^{\circ} \mathrm{C}$ (from $13.75^{\circ} \mathrm{C}$ to $14.50^{\circ} \mathrm{C}$-estimated from a graph) in this same period. Assuming that this water temperature increase is for all of the main water surfaces of the planet and selecting any initial water temperature, we can verify mathematically whether the evaporation increased or decreased in this period. Although the average air temperature of the planet certainly is higher than these values because the temperatures of the Southern Hemisphere are much higher than these ones, let's adopt them. Thus, for the initial conditions of $t_{w}=$ $20^{\circ} \mathrm{C}, t_{a}=13.75^{\circ} \mathrm{C}, V=2.5 \mathrm{~m} / \mathrm{s}, \phi=0.60$, we have

$$
\begin{aligned}
& E=0.0041(2.5)^{0.8}(1.2)^{-0.2}(2335.81-0.60 \times 1571.70) / 101325 \\
& E=0.0001131 \mathrm{~kg} / \mathrm{m}^{2} \cdot \mathrm{s}=0.407097 \mathrm{~kg} / \mathrm{m}^{2} \cdot \mathrm{h}
\end{aligned}
$$

And for the new conditions of $t_{w}=20.50^{\circ} \mathrm{C}, t_{a}=14.50^{\circ} \mathrm{C}$, we have

$$
\begin{aligned}
E & =0.0041(2.5)^{0.8}(1.2)^{-0.2}(2409.46-0.70 \times 1649.95) / 101325 \\
E & =0.0001019 \mathrm{~kg} / \mathrm{m}^{2} \cdot \mathrm{s}=0.366746 \mathrm{~kg} / \mathrm{m}^{2} \cdot \mathrm{h}
\end{aligned}
$$

which results confirm this author's expectation that the evaporation decreased in this period in places where similar conditions applied. This is also in perfect agreement with the surveys [11] [12]. As known from basic laws, the evaporation per square meter and unit of time increases with the wind velocity and water temperature increase and decreases with the air temperature, humidity and atmospheric pressure increase. Any combinations of these variables can be calculated through Equation (7) and produce results such as these of the present paper and should be analyzed carefully. Places more humid show lower evaporation than dry ones in the same way as clothes dry slower during a wet day. Places more humid obviously have more precipitation than dry ones. The higher the precipitation, the higher the humidity and consequently lower is the evaporation. Hence, more precipitation is perfectly and naturally conciliatory with less evaporation, contrarily to what is supposed by [13] [14], for example, and their nonsense concepts and "solutions" for the "evaporation paradox". It is elemental that in a humid place the evaporation is lower than in a dry one. It should also be noted that the lots of tons of water va- 
por emissions by fossil fuel and nuclear power plants, industries, vehicles and other direct human-induced sources constantly increase the humidity, which one also reduces the evaporation while increases the precipitation.

The calculation C8 has been performed for a shallow water surface for an open atmosphere (see [7]) where the forced convection predominates. However, if we consider that this free water surface is totally enclosed by a full cloud cover and thus a full greenhouse effect is established, the evaporation happens within an atmosphere with very small air movements (no wind) and consequently with free convection. When we put a cover over a free water surface we suppress the wind but not the convection which only changes from forced to free convection. As a consequence, we also make the evaporation to change from the advection mode to the diffusion mode where the evaporation and the heat by convection depend on temperature differences and not on the bulk or gross motion of the fluid over the water surface. If the Earth's cloud cover continues “closing” the planet and hence if the Earth's greenhouse effect due to the cloud cover continues increasing, the corresponding evaporation and heat by convection will happen according to the way just described for a water surface hypothetically closed.

The behavior of a greenhouse formed by the cloud cover is very similar to that of a common greenhouse where there is evaporation (e.g., a solar still) and thus the corresponding evaporation happens in free convection and is calculated by an equation that is based on the Nusselt, Prandtl, Grashof and Rayleigh numbers, on Bowen-Sartori equation [4], and takes into account the density gradient effect caused by temperature and composition gradients of the atmospheric air [5]. This Sartori equation converted to the environmental temperatures range and made explicit the atmospheric pressure becomes:

$$
E=\left(59.628 \times 10^{-5}\left[\left(t_{w}-t_{a}\right)+\left(P_{w}-\phi P_{a}\right) /\left(2.64233 P-P_{w}\right)\left(t_{w}+273.15\right)\right]^{1 / 3}\left(P_{w}-\phi P_{a}\right)\right) / P
$$

Applying Equation (8) for the same conditions of the shallow water surface C8 let's see what happens with the evaporation when it is submitted to the full greenhouse effect caused by a full cloud cover:

$$
\begin{gathered}
E=\left(59.628 \times 10^{-5}[(32-30)+(4750.96-0.70 \times 4239.65) /(2.64233 \times 101325-4750.96)(305.15)]^{1 / 3}\right. \\
\times(4750.96-0.70 \times 4239.65)) / 101325 \\
E=0.00001675 \mathrm{~kg} / \mathrm{m}^{2} \cdot \mathrm{s}=0.060300 \mathrm{~kg} / \mathrm{m}^{2} \cdot \mathrm{h}
\end{gathered}
$$

As expected, the evaporation in a greenhouse effect due to the full cloud cover and free convection is much lower than that from free water surfaces submitted to forced convection, even for shallow water layers of higher water temperatures, as already demonstrated physically [5] [7]. That is, although evaporation is a strong function of the water temperature, it is incorrect to state that the evaporation increases based solely on the water temperatures when there is the greenhouse effect caused by the full cloud cover and in comparison with the corresponding open system.

The calculation C10 has been carried out for an increased Earth's greenhouse effect due to the cloud cover increase but where the forced convection predominates. Now, let's consider the same conditions of C10 but taking into account that the planet hypothetically became completely closed by clouds in the last 50 years and then where the free convection predominated. Thus, Equation (8) applies:

$$
\begin{gathered}
E=\left(59.628 \times 10^{-5}[(20.5-14.5)+(2409.46-0.70 \times 1649.95) /(2.64233 \times 101325-2409.46)(293.65)]^{1 / 3}\right. \\
\times(2409.46-0.70 \times 1649.95)) / 101325 \\
E=0.00001438 \mathrm{~kg} / \mathrm{m}^{2} \cdot \mathrm{s}=0.051768 \mathrm{~kg} / \mathrm{m}^{2} \cdot \mathrm{h}
\end{gathered}
$$

Therefore, according to the given conditions, the evaporation of the last 50 years decreased for the places of the Earth hypothetically closed by clouds, as previously expected by this author, and confirms once again that more precipitation is perfectly conciliatory with less evaporation and the "evaporation paradox" and its referred solutions are non-sense considerations. Since the planet obviously was not submitted to the full cloud cover, the most realistic evaporation decrease for the considered conditions falls between the results of C10 and C12. This is in perfect agreement with well-known works which have shown that the evaporation and the surface radiation 
decreased while the precipitation, humidity and cloudiness increased in many countries of the world in the last decades (see [7]). Since in the last 50 years the cloudiness, the precipitation, the humidity and the temperatures increased while the evaporation and surface radiation decreased in some places of the world, this is the perfect proof that the Earth's greenhouse effect due to the cloud cover for the corresponding regions has increased. When the greenhouse effect due to the cloud cover increases in an atmosphere where there is evaporation, automatically the inner water and air temperatures and the air humidity increase while the evaporation and the surface radiation decrease. So is the way how greenhouses work and this is theoretically demonstrated [5] [7]. The increase of humidity, precipitation and of the water and air temperatures along with decreased surface radiation, evaporation and wind is possible only with the increasing presence of the greenhouse effect due to the cloud cover. The $\mathrm{CO}_{2}$ is not dense and thus does not own the property of reducing the convection and the wind.

For the $\mathrm{C} 6$ conditions in relation to the $\mathrm{C} 1$ ones, if the air temperature increased too much but the water temperature remained the same $20^{\circ} \mathrm{C}$, we would find the following super interesting result, but already calculated, experimentally verified and previewed [4] [5]:

$$
\begin{gathered}
E=0.0041(2.5)^{0.8}(1.2)^{-0.2}(2335.81-0.70 \times 4239.65) / 101325 \\
E=-0.000051317 \mathrm{~kg} / \mathrm{m}^{2} \mathrm{~s}=-0.18474 \mathrm{~kg} / \mathrm{m}^{2} \cdot \mathrm{h}=0.185 \mathrm{~mm} / \mathrm{h} \text { (condensation!) }
\end{gathered}
$$

That is, when the air dew point temperature is higher than the surface temperature, condensation of the water vapor of the air onto the surface happens, as already verified theoretically and experimentally with high agreement between them [4] [5]. This is also another demonstration and confirmation that the evaporation decreases too much when the air temperature increases and in a humid environment it can also be reversed into condensation (dew). No one of the other existing equations for evaporation can calculate the condensation of the water vapor of the air onto a surface.

This "negative evaporation" or condensation or dew serves to confirm demonstrations made above and also to elucidate other atmospheric behaviors, as follows. The atmospheric pressure $P$ is given by

$$
P=P_{d}+P_{v}
$$

where $P_{d}=$ partial pressure of the dry air, Pascal; $P_{v}=$ partial pressure of the water vapor in the air, Pascal.

So, according to the Dalton's Law of partial pressures, more water vapor in the air (by evaporation and/or by certain human activities) increases the $P_{v}$ and the local atmospheric pressure $P$ and then decreases the evaporation of the next step. However, since the emissions by certain human activities are released with very high temperatures, in the next step these ones cause expansion of portions of air and then reduce the local air pressures and create great temperature differences, which ones are also sources of big pressure differences that cause strong wind displacements (e.g., tornadoes and hurricanes). When water vapor is removed from the local air by condensation, by human techniques and/or by wind currents, $P_{v}$ and $P$ decrease and then the local evaporation of the next step increases. The rain and rainy clouds are also consequences of condensation and since this happens at lower temperatures than those of the environment, the air is cooled, reaches lower temperatures and these ones produce lower air pressures, which ones increase the potential for evaporation. However, this happens at high altitudes where the water vapor is removed for condensation, but at the surface level where the evaporation takes place the rain increases the humidity, disrupts the water vapor layer and thus reduces the evaporation. Also, the decreased local atmospheric pressure causes pressure differences which ones originate local wind currents.

The increasing "closing” of the Earth's atmosphere is made either by increase of the percentage, thickness and darkening of clouds and increase of water vapor, which conditions change the convection, evaporation and radiation behaviors. Concentrations of other greenhouse gases in the atmosphere contribute for the modification of the normal path and intensity of the incoming and outgoing radiation, but these gases and their concentrations do not have the capacity or property to affect and change the convection and evaporation behaviors, because only a thick, dense, closed and more solid cloud cover can reduce the wind, the convection, the evaporation and the radiation while it increases the temperatures. Thus, changes in the $\mathrm{CO}_{2}$ concentration cannot explain physically and scientifically the decrease of the evaporation and wind speed, which conditions also happened around the planet in the last decades (e.g., in China, Europe, USA—see [7]).

Therefore, a gas $\left(\mathrm{CO}_{2}\right)$ that supposedly is the most important one (or the only one) cannot be responsible for the creation of a full greenhouse effect around all the planet and originate all climatic consequences such as the temperatures, the wind decrease, the radiation decrease, floods, droughts, tornadoes, hurricanes, etc. The at- 
mosphere is not a monolithic iron bar where only one factor could cause all the consequences at all points of it, on the contrary, the atmosphere is gaseous and has different behaviors according to different causes and physical processes to which it is submitted in different places, and thus there are lots of other factors and causes that can change the atmospheric behaviors, as demonstrated in [7] and in this article.

The demonstrations in this paper and in [7] are based on the first principles of the physics and behaviors and not dependent on a simple and questionable coincidence of temperatures and $\mathrm{CO}_{2}$ that is not rigorous and present opposite behaviors between them along the history. Any simple coincidence may serve to pay our attention on something, but once it does not happen always and everywhere it is not valid scientifically and cannot be considered a scientific evidence or proof still more for determining the present and the future of the planet. To be valid scientifically, a coincidence must be supported by physical proofs. A simple coincidence does not mean that one factor is responsible for the other, unless it is proved scientifically before its adoption. Such "coincidence" also cannot be considered a scientific coincidence and valid comparison because the supposed global values of $\mathrm{CO}_{2}$ are officially measured only at a place of the planet and full of volcanoes in activity (Hawaii) that release thousands of tons of $\mathrm{CO}_{2}$ frequently, while the values of temperatures (anomalies) are obtained by models and statistical treatments, not just the real ones from measurements only. Of interest are the true averages of real (raw) temperatures. If the temperatures are always measured at the same points, why not to use the true values? If the real temperatures are reliable, then these ones could be used as they are to be clearer. And temperatures influenced by factors such as urban heat islands should exist. Additionally, the global land surface temperature for the $20^{\text {th }}$ Century said to be $14.3^{\circ} \mathrm{C}$ [3] cannot represent the entire planet's surface temperature because the land surface temperatures of the southern hemisphere (not the pole) are obviously much higher than this number.

Also, such as smokes and water vapor, the $\mathrm{CO}_{2}$ should not spread homogeneously around the globe and cause the stated strong full and equal greenhouse effect and warming at all places of the planet. And just in the $21^{\text {th }}$ Century, the literature (e.g., [19]) incredibly uses a rudimentary and incipient understanding of the $19^{\text {th }}$ Century to justify that the $\mathrm{CO}_{2}$ is the most important factor or the only one that generates a full and global greenhouse effect, a strong warming, uniform temperature, sea level rise and all other climate consequences, also stating that nothing more about this is in dispute. However, besides the scientific invalidations of such assumptions, the atmosphere and the Earth's surface do not behave uniformly in time and space, and only the following example invalidates such statements and beliefs of homogeneous behavior. The survey on measurements [18] reveals that the sea level in the period 1906-2008 varied $-0.70 \mathrm{~mm} / \mathrm{yr}$, which does not agree with the "global” sea level rise of $+1-2 \mathrm{~mm} / \mathrm{yr}$. Moreover, since the planet is composed by deserts and forests, the concentrations of $\mathrm{CO}_{2}$ between these two places should differ. Also, since each place of the planet has its own humid conditions and since the water vapor absorbs $\mathrm{CO}_{2}$, then each humid condition removes more or less $\mathrm{CO}_{2}$ from the atmosphere and consequently different parts of the world have different $\mathrm{CO}_{2}$ concentrations. If the $\mathrm{CO}_{2}$ spreads uniformly, then the measurements in Hawaii are influenced by volcanoes and thus their results are invalid for representing a planet's value; if the $\mathrm{CO}_{2}$ does not distribute homogeneously, then such local values of $\mathrm{CO}_{2}$ are also invalid for representing a planet's value.

The literature also tries to justify the "feedback" effect saying (e.g., [2]) that the "water vapor increases as the Earth's atmosphere warms, but so does the possibility of clouds and precipitation, making these some of the most important feedback mechanisms to the greenhouse effect”, that is, a cyclic or loop effect. The cyclic effect happens for all gases and solid particles in the atmosphere, but their amounts, velocities, regularities and distributions change, and this is what matters and it is also in these variations that the human influence happens. There are at least two fundamental errors in such kind of understanding about the atmospheric behavior. First: the water vapor does not increase as the Earth's atmosphere warms. Increase of temperature (due to a supposed greenhouse effect caused by the $\mathrm{CO}_{2}$ ) does not increase the mass of water in the atmosphere. Heat does not create mass and mass does not create mass! If the temperature increased the amount of water vapor in the atmosphere, the Sahara would be the most humid place on the planet! A warmer air has the capacity, the potential, for absorbing more water vapor, but this happens only if there is addition of moisture. If the air temperature increases but if there isn't addition of humidity, in a desert or in a warm and humid condition, the atmosphere remains with its previous amount of water vapor, being this the simplest psychrometric process called "sensible heating”, where the dry bulb temperature increases but the humidity does not increase. A warmer air can hold more water vapor, but this does not mean that it has more water vapor. Moreover, when the dry bulb temperature increases the resulting humidity can be higher, lower or equal to the previous one. Hence, it is erroneous to consider that a warming caused by a supposed greenhouse effect due to the $\mathrm{CO}_{2}$ or to other gas (except $\mathrm{H}_{2} \mathrm{O}$ ) is 
responsible for an increase of humidity (mass of water) on the planet. Thus, equivalent thoughts such as "a warmer atmosphere contains higher levels of humidity which intensify the precipitation" are also incorrect. So, floods, hurricanes and tornadoes have nothing to do with the supposed greenhouse effect caused by the $\mathrm{CO}_{2}$.

The above equivocated understanding is also accompanied by another one which believes that more water evaporates if the air temperature increases, but as demonstrated [5] [7] and in the present paper, this is also equivocated. A warmer air can hold more water vapor, but this does not mean that the evaporation is higher, because it depends on the resulting humidity. The capacity or potential of absorption of humidity does not correspond to the evaporation capacity. And such misunderstanding leads to further equivocated statements and concepts such as the followings: "Rising concentrations of carbon dioxide are warming the atmosphere. The increased temperatures result in higher evaporation rates and a wetter atmosphere, which leads to a vicious cycle of further warming" [20] or "If you increase the air temperature, more water evaporates". This is equivocated because the evaporation depends on many factors described in [5] [7] and in this paper and as seen in Equation (7) it depends on the gradient $P_{w}-\phi P_{a}$, and the relevant fact is that pressures depend on temperatures and thus evaporation depends on $t_{w}-\phi t_{a}$, which means that if $t_{a}$ increases for a same $t_{w}$ and $\phi$ the evaporation decreases. Since $P_{a}$ is an exponential function of the temperature the evaporation tends to decrease, even with a relative humidity decrease. This can also be demonstrated mathematically. Consider the common conditions C1 but now with $t_{a}=30^{\circ} \mathrm{C}$ and $\phi=50 \%$ :

$$
\begin{aligned}
& E=0.0041(2.5)^{0.8}(1.2)^{-0.2}(2335.81-0.50 \times 4239.65) / 101325 \\
& E=0.000017539 \mathrm{~kg} / \mathrm{m}^{2} \cdot \mathrm{s}=0.063141 \mathrm{~kg} / \mathrm{m}^{2} \cdot \mathrm{h}
\end{aligned}
$$

That is, the evaporation decreased even with a lower relative humidity. The same result is obtained comparing C1 and C2 with C10. All of this reveals once again that it is incorrect the belief "water vapor increases as the Earth's atmosphere warms" and similar ones such as "more water evaporates if the air temperature increases".

Moreover, the water has a thermal inertia 4.2 times greater than that of the air, which means that the air temperature fluctuates more than the water temperature. Hence, since such dependence is exponential, for a considered increase in air temperature keeping constant the other factors, the evaporation decreases too much. This is also shown [5] and in the mathematical demonstrations in this paper, where we can see that for a same $t_{\mathrm{W}}$ even with a relatively higher $V$, a higher $t_{a}$ produces evaporation from an open evaporator much lower than that for a lower $t_{a}$. High $t_{a}$ has a strong power in decreasing the evaporation, and this factor together with the greenhouse effect created by covering an open evaporator with glass or by covering the atmosphere with clouds (free convection) also explain why the evaporation has decreased in the last times [7], not increased. Therefore, increased air temperatures for a same $t_{w}$ decrease the evaporation and thus decrease the amount of water vapor and humidity in the air, contrarily to what the corresponding literature supposes (e.g., [2] [19]). So, the following understanding (e.g., [20]) "when carbon dioxide concentrations rise, more water evaporates into the atmosphere, which then amplifies greenhouse heating and then $\mathrm{CO}_{2}$ is the gas that sets up the temperature and the size of the greenhouse effect" is inconsistent.

Another equivocated and complementary understanding is the following (e.g., [3]): “As the temperature of the atmosphere rises, more water vapor is evaporated. Because the air is warmer, the relative humidity can be higher, leading to more water vapor in the atmosphere. As a greenhouse gas, the higher concentration of water vapor is then able to absorb more thermal IR radiated from the Earth, thus further warming the atmosphere. The warmer atmosphere can then hold more water vapor and so on and so on. This is referred to as a 'positive feedback loop"”. This statement is full of imperfections, which ones lead to other flawed understandings and concepts: a) when the relative humidity is higher, the evaporation is lower! b) with an air temperature rise, less evaporation can result; c) if the air is warmer, its humidity can be higher, equal or lower, and is equal or lower if there isn't addition of water vapor. Hence, a warmer atmosphere produced by the increase of the dry bulb temperature does not necessarily hold more water vapor than previously. Thus, the result may be less water vapor by evaporation and then the less amount of water vapor in the atmosphere absorbs less solar and IR radiation. The direct addition of water vapor by certain human activities increases the air humidity and then reduces the evaporation, too. So, after all, the "positive feedback loop" is unsatisfactory from the basics of the physics and atmospheric behavior. 
Second: the current understanding that the water vapor does not have influence on the atmospheric warming/cooling because it remains only about 10 days in the atmosphere together with the NASA statement [2] "but so does the possibility of clouds and precipitation” lead to the following explanation. As is now understood, the evaporation, the clouds and precipitations are not equal along the time and space and change according to the more or less intense emissions/withdrawals of water vapor, particulate matter and heat to/from the atmosphere, naturally and/or by human activities. Also, the surveys [11] [12] show that the atmospheric humidity has increased in the last times all around the planet and thus eliminate such incorrect understanding and hence the water vapor is not a "feedback", that is, it is not a null effect. Since we know that the evaporation has decreased in the last decades in many places of the world (e.g., [13]), a water vapor increase in the atmosphere is a result of direct human actions.

Transparent covers (glass, clouds, plastic, water vapor, gases) reflect, scatter and absorb and thus reduce the direct radiation entering the system (greenhouse) as well as retain a great part of the outgoing radiation from the system. Reflections by the medium are not important here because only the amount of energy entering the systems is of interest. Scatterings within the medium also do not have significance here because these redirected rays can also be absorbed by the medium. Therefore, of the above mentioned attenuations of radiation, the absorption is the most important factor regarding the storage of energy within the system and for building the greenhouse effect, because more energy stored means more energy emitted and added to the greenhouse. A thick cover reduces the transmitted radiation because the absorption of solar and IR radiation is higher, since the absorption of radiation is directly proportional to the length the ray crosses the medium. So, a thick layer of glass produces a greater greenhouse effect (which results in higher temperatures) than a thin layer of glass or plastic, all put over a box with or without water, or, if it would be possible, over the atmospheric layers of the planet. The temperatures attained by the glass cover of a solar still are much higher than the ambient temperatures, than a plastic film cover ones and than the water temperatures of an open evaporator, due to the high absorption of solar and IR radiation by the glass, which afterwards emit them to the greenhouse. These higher temperatures are also reached due to the closing effect conditions (reduced convection) produced by the glass cover. These higher temperatures are also verified in [4] [5] [21]. Although a cover reduces the direct solar radiation that enters the greenhouse, at the same time it keeps up energy inside the greenhouse and then increases its temperatures. Therefore, the reduction of energy by a transparent cover cannot be used alone for deciding about the warming of a greenhouse, in contrast to the current generalized understanding. A thick layer (or high concentration) of transparent water vapor produces a higher greenhouse effect than a thin layer (or low concentration) of transparent water vapor, or, than a thin layer (or low concentration) of another gas with a lower absorption power, such as the $\mathrm{CO}_{2}$. A gas that does not absorb radiation is not considered a greenhouse gas.

However, knowing that both the water vapor and the $\mathrm{CO}_{2}$ influence the atmospheric warming/cooling processes, it is important to know how much the contribution of both gases on the air temperature is. The current literature speech always focuses on "concentrations", thus let's see the effects of concentrations on the greenhouse effect caused by gases, not by the cloud cover. It is well known (e.g., [2]) that the $\mathrm{CO}_{2}$ has a minor effect comparatively to the water vapor on the air temperature, and [7] showed that such influence is about one percent, but the author admitted that both gases had identical index of absorption of radiation. Since the $\mathrm{CO}_{2}$ has a much smaller capacity of absorption of radiation than the water vapor, its influence on the temperature is in reality much less than one percent.

NASA [20] also says that "scientists know which wavelengths each greenhouse gas absorbs and the concentration of the gases in the atmosphere and then how much each gas contributes to warming the planet”. Let's see this, too. Figure 1 presents the well-known graph of the solar radiation wavelength spectrum with the absorption bands by different atmospheric gases. Figure 2 is an equivalent representation of Figure 1, but clearer and more didactic (there are similar ones in the literature).

It can be seen that the water vapor is the strongest absorber among all the greenhouse gases, and it is also mostly absorber in the more energetic portions of the solar and IR radiation spectrums. Its property of most absorber and its highest concentration in the atmosphere make the water vapor the most important greenhouse gas for building and changing the air temperature. Only these two properties of each gas are able to determine the current and future influence on the atmospheric warming/cooling, varying only the concentrations. These same data are also used to determine that the oxygen and nitrogen are not considered greenhouse gases. Thus, the statement (e.g., [20]) “ $\mathrm{CO}_{2}$ is the most important gas for controlling Earth's temperature” is invalid and not supported 


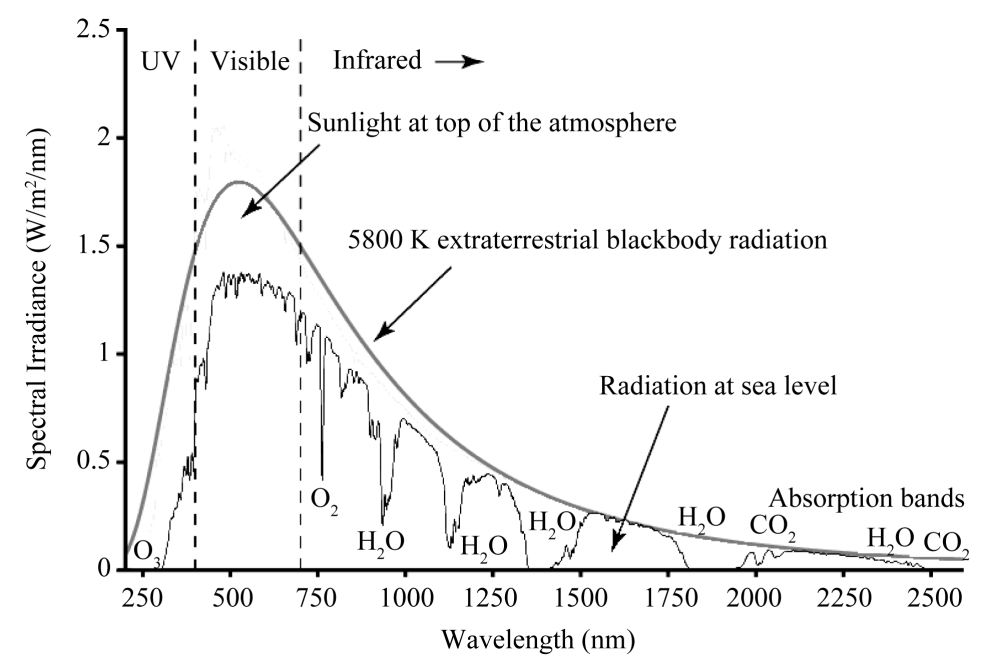

Figure 1. Solar radiation spectrum with absorption bands by different atmospheric gases.

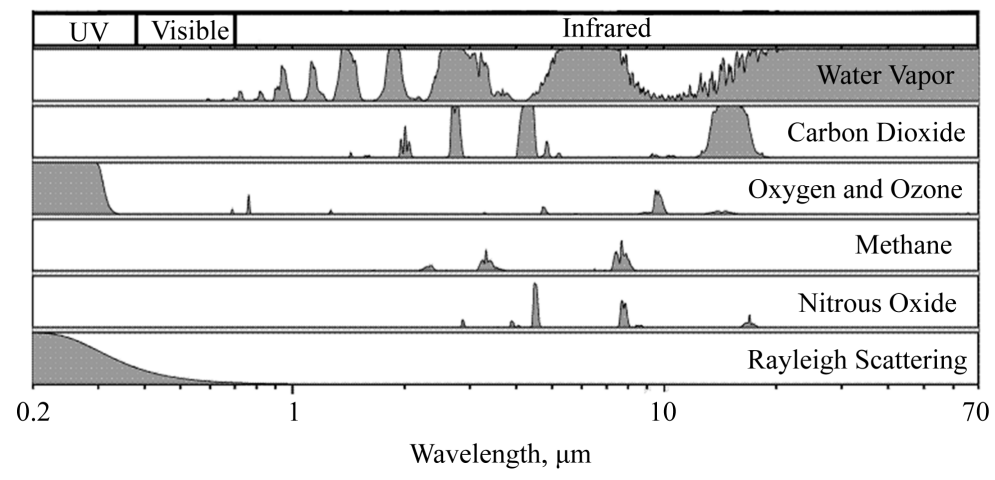

Figure 2. Solar and IR radiation spectrums with absorption bands by different atmospheric gases (Wikipedia).

by scientific analyses and thus requires scientific and consistent proof. Moreover, the NASA statement [20] "Carbon dioxide controls the amount of water vapor in the atmosphere and thus the size of the greenhouse effect" is also invalid because a tiny amount of an element $\left(\mathrm{CO}_{2}\right)$ without a special power cannot control and contain a bigger amount of another element $\left(\mathrm{H}_{2} \mathrm{O}\right)$ and with a much greater radiation absorption power, and also because the water vapor absorbs the $\mathrm{CO}_{2}$, not the contrary, as well as the water vapor affects the atmosphere in other senses, as explained in this paper and in [7]. The water vapor absorbs $\mathrm{CO}_{2}$, which interaction forms the carbonic acid $\mathrm{H}_{2} \mathrm{CO}_{3}$, and comes back with the precipitation and then a more humid air removes more $\mathrm{CO}_{2}$ from the atmosphere and also changes the heat and mass balances of the atmosphere. This chemical reaction also serves to invalidate the current thinking (e.g., [2]) that "gases that do not respond physically or chemically to changes in temperature are described as 'forcing' climate change and gases such as water vapor, which respond physically or chemically to changes in temperature are seen as 'feedbacks'”. In this case, both the $\mathrm{CO}_{2}$ and the $\mathrm{H}_{2} \mathrm{O}$ respond chemically in forming this acid and physically by altering the mass and heat balances of the atmosphere, which ones then respond to changes in temperature.

Following the logic [7] again for giving an insight on the influence of greenhouse gases on the air temperature according to their concentrations we can also estimate the influences (linearly) of other so called greenhouse gases such as methane $\left(\mathrm{CH}_{4}\right)$ and nitrous oxide $\left(\mathrm{N}_{2} \mathrm{O}\right)$ on the air temperature. For the current levels of $1.75 \mathrm{ppm}$ for the $\mathrm{CH}_{4}$ and $0.32 \mathrm{ppm}$ for the $\mathrm{N}_{2} \mathrm{O}$, the participation of each one on an average temperature of $20^{\circ} \mathrm{C}$ is about $0.00074^{\circ} \mathrm{C}$ and $0.00014^{\circ} \mathrm{C}$, respectively, that is, even considering that these gases have the same radiation absorption capacity and the same layer length of the $\mathrm{H}_{2} \mathrm{O}$, their contributions are almost nothing. As we know that the absorptions and concentrations of the $\mathrm{CO}_{2}, \mathrm{CH}_{4}$ and $\mathrm{N}_{2} \mathrm{O}$ are tremendously smaller than those of the $\mathrm{H}_{2} \mathrm{O}$ in 
the atmosphere, the corresponding influences by such gases become even smaller than the estimated ones above. Also, according to the Beer-Lambert's law, the radiation absorption by substances is directly proportional to the length through which the ray crosses and also to the concentration, that is, A $\alpha$ Lc. However, for high concentrations ( $>0.01 \mathrm{M}$-Molarity) this law is not valid because after a certain value of concentration the absorption does not increase linearly (it decelerates), thus the atmospheric gases have smaller participations in the air temperature than the ones estimated above

Moreover, for a stated $6^{\circ} \mathrm{C}$ increase in the average air temperature for 2100 (e.g., [1]—see IPCC AR4) we should have more than 20,000 ppm of $\mathrm{CO}_{2}$ in the atmosphere. However, this amount would be much higher than $5,000 \mathrm{ppm}$, a limit of allowable human exposure to the $\mathrm{CO}_{2}$, because this amount already causes deprivation of oxygen, suffocation [22]. Thus, much prior to any warming, the people would face serious problems of survival with such level of $\mathrm{CO}_{2}$. An amount of $5,000 \mathrm{ppm}$ of $\mathrm{CO}_{2}$ would correspond to an increase of much less than $2^{\circ} \mathrm{C}$ and then an increase of $6^{\circ} \mathrm{C}$ due to this gas would be almost impossible, because the world would finish much before such supposed temperatures.

The current literature links the radiation almost exclusively to the $\mathrm{CO}_{2}$ and this to the air temperature, but since the radiation is not the only factor influencing the air temperature, since the $\mathrm{CO}_{2}$ does not have the highest concentration in the atmosphere, since the $\mathrm{CO}_{2}$ is not the major absorber of radiation, since the $\mathrm{CO}_{2}$ is not sufficiently dense to be able to reduce the wind, the convection and the evaporation, since the $\mathrm{CO}_{2}$ does not have the supposed high power for increasing the air temperature too much, then there are not scientific reasons that justify the relevance of linking the radiation only to the $\mathrm{CO}_{2}$ and then to the exclusive determination of the air temperatures.

Venus is the hottest planet of our solar system and its atmospheric temperature at the surface is about $467^{\circ} \mathrm{C}$, being its atmosphere composed of about $96 \% \mathrm{CO}_{2}, 3.5 \%$ nitrogen and traces of other gases, including water vapor. Its atmospheric layer is about 100 times thicker than our own on Earth and its cloud cover composed of sulfur dioxide and droplets of sulfuric acid is also very thick and dense.

Venus is the second planet from the Sun and although receives only about $25 \%$ of the solar radiation received by the first one (Mercury), it is hotter than Mercury and thus people do not understand why. What happens is that Venus has a very thick, dense and heavy cloud cover that traps the Sun's heat and the outgoing IR radiation, while Mercury, for practical considerations, has no atmosphere, no blanket and no cover to keep up the energy. A pressure pot is more efficient and heats the food more than a common pot without cover because it traps and stores the heat, increases the temperature and thus increases the pressure inside. All the thermal processes in the atmosphere are the same, only the amounts change, and these are the same behaviors and principles demonstrated for closed and open evaporators [5], and for the "closed" and open atmospheres [7]. In these two works it is demonstrated that although the closed evaporator and "closed" atmosphere (by a transparent cloud cover) receive less energy inside, the corresponding temperatures are much higher than the open ones (closings created by a glass cover, a pot cover or a cloud cover).

Venus proves how strong the effect of a cloud cover in increasing the temperatures is. Venus clouds reflect almost all of the sunlight that hit them and the total solar energy received by the planet's surface is less than that received by the Earth's surface, but even so the temperatures below the clouds are much higher than above them and than those of the Earth's surface. Please pay attention: such high temperatures happen below the cloud deck, not above it, although above it there is much $\mathrm{CO}_{2}$, where and while the corresponding temperatures are negative.

This correct knowledge on how the greenhouse effect really works is also decisive for solving another unsolved problem [23]: "In Venus there are high-velocity winds in the upper atmosphere, but the atmosphere below the cloud deck appears to be relatively stagnant. So, the high velocity upper level winds and the contrasting stagnation of the lower atmosphere are not well understood”. The solution for this problem is given through the principles and explanations described in [5] [7] and in the present paper. When you put a cover onto a pan with or without water, you block the wind from passing directly over the water or over the dry bottom and then you convert the forced convection (wind) above the cover into the free convection (small air movements, not winds) below the cover, and then your action naturally reduces the wind (thus causes less heat loss) and the evaporation (in case of water), although the inner temperature increases. The cloud covers of ours and Venus atmospheres produce the same or equivalent effect as the glass cover for the solar still and the metallic cover for the pot. This stagnation is the proof of the effect produced by any cover.

Importantly, since gases, including the $\mathrm{CO}_{2}$, do not have the property of forming thick dense layers and strong thermal inertias, they do not have the capacity of blocking the wind or making it stagnant and also to reduce the 
evaporation. Furthermore, winds are generated by pressure differences, which ones are generated by temperature differences. The atmospheric pressure at Venus' surface is about 92 times that of Earth's, and then the very high pressure and temperatures below the cloud cover of Venus generate strong winds at the limits of its cloud layer. The heavy cloud cover and the strong atmospheric pressure of Venus are responsible for keeping the heat below it (like a pressure pot) and thus increasing the temperatures. Below the Venus' cloud cover there are very high temperatures, but not great temperature differences, which ones generate great wind speeds.

If the Earth's atmosphere was 100 times thicker than it is, a normal temperature of $20^{\circ} \mathrm{C}$ would be converted into a temperature of about $2000^{\circ} \mathrm{C}$ (linearly), that is, an Earth's temperature produced mainly by the water vapor would become greater than a Venus' temperature of $467^{\circ} \mathrm{C}$ produced by the dominant $\mathrm{CO}_{2}$. And as explained above, the $\mathrm{CO}_{2}$ is not able to increase the cloud cover, to reduce the wind speed and the evaporation, and to increase the precipitation and the humidity, as has already happened in some places of the world in the last decades (see [7]).

The current literature normally attributes the high temperatures of Venus to its high content of $\mathrm{CO}_{2}$. Is this true? No! Mercury also has high temperatures of about $427^{\circ} \mathrm{C}$ similar to those of Venus, but for practical purposes Mercury does not have $\mathrm{CO}_{2}$. OK, then Mars, which is composed by $95 \% \mathrm{CO}_{2}$ must also have such high temperatures, right? Wrong! Mars reaches only about $20^{\circ} \mathrm{C}$ at noon in summer and its yearly average is about $-55^{\circ} \mathrm{C}$. Thus, the $95 \% \mathrm{CO}_{2}$ content of the Martian atmosphere is not able to cause high warming such as the one supposed by the literature for Venus and for the less than one percent $\mathrm{CO}_{2}$ of the Earth's atmosphere. NASA [2] tries to justify stating that "Venus has about 300 times as much $\mathrm{CO}_{2}$ in its atmosphere as Earth and Mars do, producing a greenhouse effect and a surface temperature hot enough to melt lead". NASA [2] uses two weights and two measures (double standards): for Venus the highest $\mathrm{CO}_{2}$ concentration is decisive, but for Earth the low $\mathrm{CO}_{2}$ concentration is also decisive. Meanwhile, Jupiter's atmosphere does not have $\mathrm{CO}_{2}$ and receives 27 times less solar energy than Earth and 52 times less solar energy than Venus, but its temperatures below the cloud cover (the water clouds form the densest layer of clouds) vary between $\sim 50^{\circ} \mathrm{C}-180^{\circ} \mathrm{C}$, while above it there are negative temperatures. The system that stores energy (dense and heavy cloud cover) plays a powerful role and can explain these much higher temperatures than the ones on Earth, which atmosphere contains $\mathrm{CO}_{2}$.

The average solar constant $\left(\mathrm{W} / \mathrm{m}^{2}\right)$ of Mercury is 9611.4, of Venus is 2611.0, of Earth is 1366.1, of Mars is 588.6 and of Jupiter is only 50.5. Venus receives 3.5 times less solar energy than Mercury but has higher temperatures below the cloud cover than those on Mercury. Mars receives less than half of the Earth's solar energy but its temperatures below the cloud cover are similar to those on Earth. Jupiter receives less than $10 \%$ of the solar energy of Mars but its temperatures below the cloud deck are very high, while high temperatures do not happen on Mars. So, the $\mathrm{CO}_{2}$ is not important for the warming and a powerful system of accumulation of energy together with less heat loss (greenhouse effect caused by dense and closed covers) can make the planets' atmospheres to reach high temperatures. This effect can also be observed theoretically [5] and theoretically and experimentally [4], where we can see that the water temperatures of the closed evaporator (solar still) are much higher than those of the open evaporator, even at night. At the night hours, we can verify the very interesting and important effect of the closed system which accumulates energy received during the day and loses less heat, while the open one loses more heat due to the wind and due to direct irradiation to the sky. Although the closed evaporator receives less heat during the day it keeps more energy and higher temperatures during the day and night than the ones of the open evaporator.

The literature associates more clouds with a cooling effect only, because they reduce the solar radiation entering the system (greenhouse). It also believes that less energy due to the cloud effect means a cooling effect only. This is true for isolate clouds, but not always for full cloud covers. And such unique line of reasoning and immediate general adoption do not allow the discovery of the cover effects, as extensively demonstrated [5] [7] and in the present paper. Furthermore, articles from the literature normally adopt such corresponding understanding stating that evaporation cools the global climate because it creates more clouds and then these ones cool the planet. This is incorrect, because this variation depends on the cloud color (transparency), absorption characteristics, density, thickness, amount, closing conditions, geographical location, etc. Furthermore, a full cloud cover and dense water vapor trap the heat and as any cover reduce the wind and thus reduce the evaporation and the removal of heat from the air and from bodies, which conditions increase the warming below these layers, as happens in the solar still. Moreover, a cloud cover also eliminates the open sky window (8 to $13 \mu \mathrm{m}$ ) for the radiation loss from the Earth's surface and thus increases the warming below it. A full cloud cover blocks the sky temperature (in clear sky) of being very low for the high emissions of radiation from Earth, converts it 
almost to the air temperature and then more heat remains below it, because the lower part of the clouds is almost at the same surface air temperature and then radiates back with higher intensity than would do a clear sky. The radiation is proportional to the fourth power of the temperature. Also, in the last decades the clouds increased despite the fact that the evaporation decreased [13], which means that more heat remained at the surface.

A good example is the Amazon, where the sky is almost always fully covered by clouds and it rains everyday, but the weather is warm, humid and with low wind velocity. In [9] there is a mathematical comparison between the thermal behaviors of the Amazon and the Sahara, where we see that the Amazon's atmosphere is warmer than the Sahara's one. The Amazon is not an example of a cooled place. The Sahara's atmospheric warming depends on the solar radiation directly and lasts while there is solar energy, because there are almost no water vapor and no clouds to sustain and regulate the warming, whereas the Amazon's atmosphere keeps up the heat and humidity for a longer time. During the day, the Sahara reaches very high temperatures $\left(50^{\circ} \mathrm{C}-60^{\circ} \mathrm{C}\right)$, but at night reaches very low temperatures including those below zero, while the Amazon's temperatures are kept almost in the same level during the day and night along the year $\left(\sim 26^{\circ} \mathrm{C}-34^{\circ} \mathrm{C}\right)$. It is clear the presence of the process of energy storage by the water vapor and cloud cover. Cities rounded by mountains are much warmer than others because the air remains stagnant and this works as a cover that traps the heat and humidity causing weak removal of heat and humidity from the skin. Since the Sahara's atmosphere certainly has a lower level of $\mathrm{CO}_{2}$ than the Amazon's one, such low level is not responsible for the very high temperatures of that desert as well as the Amazon's higher level of $\mathrm{CO}_{2}$ is also not responsible for the corresponding lower temperatures than those of the Sahara.

Ice cores with their air bubbles have been utilized to “determine” "past” atmospheric warming or cooling. Ice cores are extracted by drilling devices that release a lot of heat to the samples and these are also transported to laboratories by vehicles and thus suffer direct influence of the corresponding environments and manipulations, which transfer heat to the ice cores. In laboratories the samples are fractioned and stored, which manipulations also change the original conditions of the ice. Moreover, local measurements cannot be generalized for the entire globe. Besides the introduction of these scientific errors and many others in the results, let's see whether ice cores can be considered or not a correct means for determining such temperatures of the long past. Due to the high heat-temperature-sensitive nature of the ice cores, please respond: which solid material, brick or ice, transfers heat by conduction faster? Those who answered "brick" gave the wrong answer. The thermal conductivity (k) of brick (common) at $25^{\circ} \mathrm{C}$ is $0.60 \mathrm{~W} / \mathrm{mK}$ and the $\mathrm{k}$ for ice $\left(-25^{\circ} \mathrm{C}\right.$ ) is $2.45 \mathrm{~W} / \mathrm{mK}$, that is, ice transfers 4.1 times faster than bricks the same amount of heat received. Bricks absorb more heat (short wave absorptivity $=$ $55 \%$ ) than ice (31\%), of course, but they are 4.1 times slower in transferring the heat received. For comparison, the $\mathrm{k}$ of asphalt $\left(25^{\circ} \mathrm{C}\right)$ is $0.75 \mathrm{~W} / \mathrm{mK}$ and the $\mathrm{k}$ of dry sand $\left(25^{\circ} \mathrm{C}\right)$ is $0.15-0.25 \mathrm{~W} / \mathrm{mK}$ [24]. A common wall of bricks (about $0.15 \mathrm{~m}$ wide) lasts about 4 hours to transfer the heat received from one side to the other. Then, a wall of ice with the same width would need about one hour to transfer the same amount of heat from one side to the other. Therefore, the heat accumulated and its variations in ice cores supposed to be from thousands or millions years ago can be in reality from some hours ago only, and also vary according to the heat gained during transportation and manipulations. The mass of air trapped in ice cores may be old, but the corresponding temperatures are not. And the relevant understanding is to know whether humans can affect the climate nowadays independent of ancestral times and solar energy variations, as already shown in [7] and in the present paper. Conceptualizations that generate more uncertainties than convictions should be left aside.

\section{Conclusions}

This paper analyzes and describes physically and mathematically the atmospheric behavior based on the correct theoretical principles that drive us in the right directions. Top concepts adopted by the current literature on climate changes or atmospheric warming are not in agreement with the first principles of the physics. For example, the literature believes that the radiation is the only factor that influences and changes the air temperature, but this violates the law of conservation of energy and has also been demonstrated physically and mathematically in the paper. Also, the Sun is not the only heat source for the atmosphere because there is generation of heat at the Earth's surface by human activities.

It is also shown that the water vapor is not a null effect and it cannot be removed from the atmosphere for temperature, greenhouse effect and climatic changes considerations, and thus the "feedback" concept is invalid, in contrast to what is adopted by the current science, where many equivocated concepts come from equivocated understandings. 
The current literature also says that "water vapor increases as the Earth's atmosphere warms", but this is also incorrect because heat (from a supposed greenhouse effect due to the $\mathrm{CO}_{2}$ ) does not create mass (of water). The above equivocated understanding is accompanied by another one which believes that more water evaporates if the air temperature increases. This is also flawed because evaporation depends on many factors and can decrease even with an air temperature increase. These demonstrations together with other authors' surveys showing that in the last decades the planet became wetter eliminate the literature concept that the water vapor does not have influence on the atmospheric warming/cooling.

It is also seen that although evaporation is a strong function of the water temperature, it is incorrect to state that evaporation increases based solely on the water temperature when there is the presence of the greenhouse effect caused by the full cloud cover. It is very important to know that although a closed system (greenhouse) formed by a glass cover or by a cloud cover receives less energy, its temperatures inside may be higher and the evaporation lower than the corresponding ones of an open system. So is the way how greenhouses really work.

Yes, certain human activities can influence the climate, but not as has been said by the current literature. For example, if one drop of water is thrown upward, one drop of water will come back, and fossil fuel and nuclear power plants, industries, vehicles, etc, have thrown millions of tons of water upward every second around the globe, and then much water has come back irregularly in amounts, time and space. This is easy to understand and to agree and is physically and mathematically expressed by the New Hydrological Cycle discovered by Sartori. This is totally different than the equivocated belief which removes the water from the atmospheric heat and mass balances and even so says that all climate changes (floods, for example) originate from a warming due to a "greenhouse effect caused by the $\mathrm{CO}_{2}$ ". Such understanding is flawed because $\mathrm{CO}_{2}$ and heat do not create mass of water or any other mass! Certain human activities have also thrown thousands of tons of particulates every second around the world and then created "solid" barriers in the air and thus generated droughts in uncertain places and periods.

The mathematical formulations of the conventional and of the New Hydrological Cycle have been extended to the conventional (no human influence) and to the human-influenced $\mathrm{CO}_{2}$ cycle.

It is solved the problem on why the wind speed on Venus is very high above the cloud deck while it is stagnant below it, being this the same physical principle valid for the Earth's cloud cover. It is demonstrated that the $\mathrm{CO}_{2}$ does not have significant importance for building and changing the temperatures of Venus, Mars, Mercury, Jupiter and Earth.

Ice cores are not valid for "determining" "past" temperatures of the planet, because besides the many scientific errors introduced in the measurements due to transportations and manipulations, the mass of their air bubbles may be old, but the corresponding temperatures are not.

\section{References}

[1] IPCC (2014) http://www.ipcc.ch

[2] NASA (2014) A blanket around the Earth. http://climate.nasa.gov/causes

[3] NOAA (2014) Greenhouse Gases—Water Vapor. http://www.ncdc.noaa.gov/monitoring-references/faq/greenhouse-gases.php

[4] Sartori, E. (1987) A Mathematical Model for Predicting Heat and Mass Transfer from a Free Water Surface. Proceedings of ISES Solar World Congress, Hamburg, 3160-3164.

[5] Sartori, E. (1996) Solar Still versus Solar Evaporator: A Comparative Study between Their Thermal Behaviors. Solar Energy, 56, 199-206. http://dx.doi.org/10.1016/0038-092X(95)00094-8

[6] Sartori, E. (2006) Convection Coefficient Equations for Forced Air Flow over Flat Surfaces. Solar Energy, 80, 10631071. http://dx.doi.org/10.1016/j.solener.2005.11.001

[7] Sartori, E. (2012) The Physical Principles Elucidate Numerous Atmospheric Behaviors and Human-Induced Climatic Consequences. Open Journal of Applied Sciences, 2, 302-318. http://dx.doi.org/10.4236/ojapps.2012.24045

[8] Sartori, E. (2000) A Critical Review on Equations Employed for the Calculation of the Evaporation Rate from Free Water Surfaces. Solar Energy, 68, 77-89. http://dx.doi.org/10.1016/S0038-092X(99)00054-7

[9] Sartori, E. (2013) Evaporation and the Planet. http://sartori-globalwarming.blogspot.com

[10] van Vliet, M.T.H., Yearsley, J.R., Ludwig, F., Vögele, S., Lettenmaier, D.P. and Kabat, P. (2012) Vulnerability of US and European Electricity Supply to Climate Change. Nature Climate Change, 2, 676-681. http://dx.doi.org/10.1038/nclimate1546 
[11] Alexander, L.V., Zhang, X., Peterson, T.C., Caesar, J., Gleason, B., Klein, T.A., Haylock, M., Collins, D., Trewin, B., Rahimzadeh, F., Tagipour, A., Rupa, K.K., Revadekar, J., Griffiths, G., Vincent, L., Stephenson, D.B., Burn, J., Aguilar, E., Brunet, M., Taylor, M., New, M., Zhai, P., Rusticucci, M. and Vazquez-Aguirre, J.L. (2006) Global Observed Changes in Daily Climate Extremes of Temperature and Precipitation. Journal of Geophysical Research, 111, DO5109. http://dx.doi.org/10.1029/2005JD006290

[12] Groisman, P.Y., Knight, R.W., Easterling, D.R., Karl, T.R., Hegerl, G.C. and Razuvaev, V.N. (2005) Trends in Intense Precipitation in the Climate Record. Journal of Climate, 18, 1326-1350. http://dx.doi.org/10.1175/JCLI3339.1

[13] Brutsaert, W. and Parlange, M.B. (1998) Hydrological Cycle Explains the Evaporation Paradox. Nature, 396, 30. http://dx.doi.org/10.1038/23845

[14] Roderick, M.L. and Farquhar, G.D. (2002) The Cause of Decreased Pan Evaporation over the Past 50 Years. Science, 298, 1410-1411.

[15] Sartori, E. (2003) Letter to the Editor. Solar Energy, 73, 481.

[16] Kaplani, E. and Kaplanis, S. (2014) Thermal Modeling and Experimental Assessment of the Dependence of PV Module Temperature on Wind Velocity and Direction, Module Orientation and Inclination. Solar Energy, 107, 443-460. http://dx.doi.org/10.1016/j.solener.2014.05.037

[17] Sartori, E. (2014) Accuracy of Convection Coefficient Equations for Forced Air Flow over Flat Surfaces. http://www.scribd.com/doc/239567869/Accuracy-of-convection-coefficient-equations

[18] Araújo, I.B., Bos, M.S., Bastos, L.C. and Cardoso, M.M. (2013) Analysing the 100 Year Sea Level Record of Leixões, Portugal. Journal of Hydrology, 481, 76-84. http://dx.doi.org/10.1016/j.jhydrol.2012.12.019

[19] NASA (2014) Climate Change: How Do We Know? http://climate.nasa.gov/evidence/

[20] NASA (2014) Effects of Changing the Carbon Cycle. http://earthobservatory.nasa.gov/Features/CarbonCycle/page5.php

[21] Al-Mahdouri, A., Gonome, H., Okajima, J. and Maruyama, S. (2014) Theoretical and Experimental Study of Solar Thermal Performance of Different Greenhouse Cladding Materials. Solar Energy, 107, 314-327.

[22] WDHS—Wisconsin Department of Health Services (2014). http://www.dhs.wisconsin.gov/eh/chemfs/fs/carbondioxide.htm

[23] UTK-University of Tenessee Knoxville (2014) The Atmosphere of Venus. http://csep10.phys.utk.edu/astr161/lect/venus/atmosphere.html

[24] TET—The Engineering Toolbox (2014) www.engineeringtoolbox.com 